\title{
LECTURAS INTERTEXTUAL E INTERDISCURSIVA EN SOCIOCRÍTICA
}

\author{
Jorge Ramírez Caro \\ Universidad de Costa Rica \\ Universidad Nacional, Costa Rica
}

Uno de los problemas más debatidos por la postmodernidad es la ruptura de los paradigmas y de las nociones establecidas por el modernismo. Dentro de la teoría literaria se ha experimentado la pérdida de las nociones de autor, texto y lector, y a ello ha contribuido la teoría de la intertextualidad, considerada no sólo como una práctica de escritura autoconsciente y autorreflexiva, sino también como una práctica de lectura. Unida a la noción de intertextualidad aparece la de interdiscursividad, entendida como la manifestación heteroglósica o polifónica de los textos o como la expresión de la ideología y la formación discursiva de las formaciones sociales por las que atraviesa el texto.

Antes de detenernos en los planteamientos de la sociocrítica en torno a las lecturas intertextual e interdiscursiva, conviene revisar el panorama de la intertextualidad modernista y postmodernista, según nos lo muestran Manfred Pfister ${ }^{1}$ y Pavao Plavlicic ${ }^{2}$. Pfister apunta que la postmodernista es una cultura parasitaria, hecha de y a partir de

1. M. Pfister, “¿Cuán postmoderna e s la intertextualidad?”, Criterios 29 (La Habana, enero-junio, 1991) 3-24.

2. P. Pavlicic, "La intertextualidad moderna y postmoderna", Criterios 30 (La Habana, julio-diciembre, 1991) 65-87. 
matcriales y procedimientos dados de antemano. La realidad es algo que no se experimenta directa e inmediatamente, debido a que ésta nos llcga siempre de manera pre-estructurada por el lenguaje,pre-formada por la cultura y filtrada a través de los medios masivos (que son otros mensajes): el nuestro es un mundo y un laberinto de espejos, nada de lo que vemos es real.

Dentro de esta perspectiva, apunta Pfister, el arte, más que un acto de creación, se reduce a reciclar y transformar los sobrantes de la cultura anterior y los desperdicios de la vida moderna. La originalidad sólo sobrevive en la forma de los juegos sofisticados que se establezcan con los textos existentes y las estructuras tradicionales por medio de la alusión, la cita, la parodia y el collage: cada texto termina atrapado en una red de relaciones y referencias con otros textos. Aunque practicada desde la antigüedad, ha sido bajo el postmodernismo que se ha teorizado la intertextualidad: el nuevo texto no siempre se ha referido a la realidad, sino que está escrito encima de uno anterior. En el texto postmodernista, la realidad social ha desaparecido detrás de las palabras.

Al establecer la diferencia entre la intertextualidad moderna y la postmoderna, Pfister señala que la primera no es autoconsciente ni autorreflexiva, sus pretextos son canonizados y normativos, prestigiosos y reconocidos, mientras que la postmodernista trabaja sobre productos de la cultura de masas, mitos, clichés de la cultura pop y de la alta cultura ${ }^{3}$ : la intertextualidad es puesta en primer plano, exhibida, tematizada y teorizada como un principio constructivo central. La intertextualidad siempre implica alguna referencia interpretativa y perspectivizante de otros textos:

El texto postmodernista del tipo ideal es, pues, un metatexto, o sea, un texto sobre textos o sobre la textualidad, un texto

3. "El museo imaginario del postmodernismo es una mezcla de azar, de pasado y presente, de clásico y pop, arte y comercio, todos ellos reducidos al mismo status de materiales desechables y estímulos de superficie”, Pfister, 18-19. 
autorreflexivo y autorreferencial, que tematiza su propio status textual y los procedimientos en que está basado ${ }^{4}$.

Por su parte, Pavlicic ofrece algunos otros rasgos distintivos entre el arte moderno y el postmoderno para después señalar, cómo cs entendida la intertextualidad en cada uno de ellos. La actitud del arte modernista frente al pasado es de ruptura, mientras que el postmoderno tiende a la continuidad, al incluir dentro de sí el pasado; en el modernismo, los períodos estéticos nacen en oposición a la época anterior; en cambio, el postmodernismo toma en cuenta toda la tradición precedente; el modernista parte de la premisa de que ha llegado un tiempo nuevo y que en él todo debe ser diferente de lo que era antes: sólo necesita del pasado para oponérsele; el postmodernista considera que el pasado no puede ser desechado porque no sabe si puede decir algo nuevo y lo sobrecoge la idea de que todo discurso sea en realidad un recuento; tiene la certeza de que el pasado está en el presente: para que el nuevo texto se entienda debe tener dentro de sí lo viejo y el lector debe estar entrenado en los viejos textos. Es esta actitud frente al pasado la que lleva al arte postmoderno a preocuparse más por el arte que por la realidad: le interesan más las convenciones y procedimientos artísticos que el tratar de arreglar el mundo y dar testimonio de él:

Aspirando a incluir dentro de sí todo pasado, a establecer alguna relación con la tradición entera, el arte postmoderno reaviva ese pasado, lo revaloriza, lo comenta y entra en un diálogo con él ${ }^{5}$.

Las relaciones intertextuales en las dos épocas se producen por motivos diferentes: el modernismo, al buscar crear lo nuevo ve en lo viejo el adversario polémico, mientras que en el postmoderno lo vicjo

4. Pfister, 14.

5. Pavlicic, 67. 
es interlocutor y maestro y es reavivado en el nuevo texto. Según Pavlicic, las diferencias entre la intertextualidad modernista y la postmodernista se dan en tres niveles:

a) en cuanto al objeto: el texto modernista echa mano de textos concretos, citas, fragmentos, para destruirlos tratándolos como símbolos de lo viejo o proclamarlos precursores y desdeñarlos como viejos; los textos postmodernistas, en cambio, trabajan sobre conjuntos de textos que remiten a todo un género, a toda una época o a una convención literaria: no rechazan nada, sino que desean conservarlo todo; lo pasado se inserta en lo que será una síntesis del presente;

b) en cuanto a la forma: en el arte moderno el diálogo intertextual se realiza en forma de cita, alusión, polémica, travesti, parodia y otros modos diversos donde se reconoce el texto antiguo y la forma en que el nuevo texto se relaciona con el anterior; mientras que en el postmodernismo se da por medio de seudocitas y mistificaciones de obras inexistentes;

c) en cuanto a la función:

el objetivo del establecimiento modernista de vínculos intertextuales es la adición de nuevos significados a un nuevo texto, mientras que el objetivo del establecimiento postmodernista de tales vínculos es la adición de un nuevo texto a los significados ya existentes. Cuando tal vínculo se establece en el modernismo, en el centro de la atención está el nuevo texto; cuando se establece en el postmodernismo, el viejo texto. En el modernismo se afirma lo nuevo y la novedad de lo nuevo; en el postmodernismo, lo viejo y la eternidad de lo viejo ${ }^{6}$.

6. Pavlicic, 70-71. 
Finalmente, en cuanto a la concepción de texto, también se pueden establecer diferencias entre modernos y postmodernos. Los primeros conciben el texto como texto y los segundos como intertexto:

La premisa de la obra moderna es que todas sus cualidades esenciales sean buscadas en ella misma; la premisa de la obra postmoderna es que todas sus cualidades esenciales sean buscadas en su relación con las otras obras literarias. En el modernismo el texto literario es concebido como un sistema encerrado en sí mismo, como un todo redondeado... Todo lo que hay que saber sobre el texto, el lector llega a saberlo por el texto mismo... Con sus aspectos abiertos, la obra literaria moderna está abierta ante todo hacia la realidad, y no hacia otras obras literarias ${ }^{7}$.

La intertextualidad moderna hace que el nuevo texto incluya el viejo con una relación de ruptura: el nuevo texto rompe con el anterior y lo incrusta en su propio sistema semántico por medio de mecanismos destructivos, de modo que del viejo texto quede apenas algo. El nuevo texto utiliza sólo trozos de textos anteriores y no totalidades: "las citas son tales que aquello de lo cual se cita suele ser borrado hasta que sea irreconocible". El texto viejo está al servicio del nuevo:

El texto al que se remite la obra modernista es tratado por lo regular como un material, como algo que está sujeto a reelaboración, como está sujeto a reelaboración el material de la realidad... Lo nuevo es el sujeto, lo viejo es sólo el objeto ${ }^{8}$.

Para los postmodernos, por el contrario, el texto literario no puede ser autónomo: "ningún texto literario es comprensible fuera de su relación con otros textos":

7. Pavlicic, 72.

8. Pavlicic, 73. 
en el momento en que es construido como texto, entra en una red muy complicada de relaciones con otros textos (literarios y no literarios) con los que es comparado, con la ayuda de los cuales es interpretado, para que después, como a un texto artístico aparte..., se le confiera precisamente cierto significado, asignándole un puesto entre los otros textos ${ }^{9}$.

El texto ya no está separado, ni cerrado, ni es autosuficiente, ni siquiera es el centro de la acción literaria misma.

Si el texto ya no está cerrado ni es autosuficiente, entonces tampoco la intertextualidad puede ser tal que el nuevo texto reelabore e incluya dentro de sí completamente al viejo, sino que debe ser tal que le permita al viejo texto conservar la integralidad y participar con todos sus significados en la relación intertextual... Así, el nuevo texto no le impone significados al viejo, ni los censura, sino que le deja la posibilidad de que hable él mismo ${ }^{10}$.

Pavlicic apunta otras diferencias entre la intertextualidad moderna y la postmoderna. La relación entre el texto nuevo y el viejo en la moderna es metafórica, mientras que en la postmoderna es metonímica. El texto modernista entra en diálogo con otro texto antiguo a través de alguna semejanza temática o de motivo, estilo, verso: la comparación con el viejo texto le confiere cierta cualidad al nuevo que sin aquél éste no tendría. Pero la semejanza con lo viejo es para distanciarse de él y hacer emerger una tercera cosa que no es semejante a ninguno de cllos. Mientras tanto, en el postmodernismo los textos viejos y recientes no se vinculan en consideración a cierta semejanza entre ellos, sino en consideración a alguna coincidencia lógica o de sentido: el viejo texto viene a completar e ilustrar al nuevo.

9. Pavlicic, 73-74.

10. Pavlicic, 74-75. 
Ambos tipos de intertextualidad demandan diversas aptitudes del lector hacia los textos, distintos tipos de competencias de éste y aspiran a influir en él de diferentes maneras. La intertextualidad moderna es retórica: está acentuada, siempre se realiza plenamente, nunca se alude; se le llama la atención al lector sobre el acto intertextual y se le induce a que él prevea este acto: por medio de las marcas, el autor le hace un guiño al lector para que éste construya el significado previsto por aquél. De este lector no se espera ninguna competencia particular para descubrir el vínculo intertextual ni la comprensión del significado: sólo se demanda que descubra el vínculo y comprenda el significado afincado en el texto. El lector acepta o rechaza el vínculo.

En cambio, la intertextualidad postmoderna no es acabada sino abierta, no es manifiesta, sino oculta. "Puede ser realizada sólo como alusión: el vínculo se realiza en un aspecto aislado y de manera muy mediata, de manera que no es fácil establecer si existe". Su significado no es ni global ni definitivo. Del lector se espera un alto grado de competencia para determinar, primero, el vínculo intertextual, después participar en su realización, definir el sentido del vínculo y dar su propia interpretación del mismo: no se le pide que acepte o rechace lo que el texto ya hizo por él, sino que contribuya conscientemente a su creación. En definitiva, al lector se le propone que participe y construya su propia versión del texto, descubra o no los vínculos intertextuales. "El lector más competente verá más, pero ni siquiera el incompetente se verá totalmente impedido, ni podrá dejar de participar"11.

La teoría de la intertextualidad no sólo se maneja en términos de moderna o postmoderna, sino que su definición y su empleo en el análisis literario es muy variado y complejo. Ya en 1986, S. Vulture ${ }^{12}$

11. Pavlicic, 87.

12. S. Vulture, "La place de l'intertextualité dans les théories de la réception du texte littéraire”, Cahiers roumains de 'études littéraires, vol. 3 (1986). Seguimos la síntesis propuesta por M. Amoretti, "La intertextualidad: un ensayo metacrítico", Revista de Filología y Lingüistica de la Universidad de Costa Rica, vol. XII, no 2 (juliodiciembre, 1996) 7-14. 
había indicado las tres orientaciones básicas seguidas a la hora de pensar la intertextualidad:

a) lo intertextual como factor de producción o transformación: un texto sólo puede generarse desde otro texto: aquí el texto es visto como una transtextualidad infinita, una red de textos que se superponen e interceptan. La significancia es el movimiento transformador de los intertextos ${ }^{13}$."El texto es intertextualidad, escena de la significancia, escena de su propia producción"14. Representan esta propuesta Kristeva, Derrida y Barthes.

b) lo intertextual como huella reconocible en la percepción del texto a partir de la cual se orienta la lectura: al orientar la lectura y posibilitar una referencialidad cruzada, la intertextualidad no permite una lectura lineal, sino de volumen: "la lectura es una dialéctica memorial entre el texto que el lector descifra y los textos que el lector recuerda ${ }^{15}$. Aquí puede mencionarse a Riffaterre como propulsor de esta propuesta.

c) lo intertextual como hipercodificación: considera Eco que el texto posee elementos metacomunicacionales que orientan al lector en el modo de recepción y consumo del texto.

La competencia intertextual se convoca en el interior del texto bajo la forma de esquemas narrativos o retóricos que, una vez reconocidos por el lector, orientan su actividad de desciframiento según un principio de expectativas satisfechas o frustradas ${ }^{16}$.

Dentro de este marco general es que conviene ver los planteamientos teóricos y operativos de la sociocrítica sobre la intertextualidad,

13. María Amoretti, “La intertextualidad: un ensayo metacrítico”, Revista de Filología y Lingüística de la Universidad de Costa Rica, vol. XXII, n” 2 (julio-diciembre, 1996) 8.

14. María Amoretti, Diccionario de términos asociados en teoría literaria (San José: Editorial Universidad de Costa Rica, 1992) 69.

15. Amoretti, Diccionario, 69.

16. Amoretti, "La intertextualidad...", 8. 
la interdiscursividad y la lectura desde estos dos mecanismos constructores de sentido ${ }^{17}$. Ya sabemos que el centro de interés de la sociocrítica de la escuela de Montpellier representada por Edmond Cros es la genética textual, punto generador de todo el porvenir del texto. Cada texto de ficción posee unos elementos que programan lo que va a ser el texto. Este conjunto de elementos reciben el nombre de genotexto, constituido por el autoengendramiento, la intertextualidad y la interdiscursividad. Estos tres componentes del genotexto forman parte del proceso de escritura, de la producción del texto y, junto con el mito y el símbolo, integran las estructuras de mediación que intervienen en el proceso de transformación de la realidad observable en texto ficcional ${ }^{18}$ : el fenómeno textual viene a ser el producto de este haz de elementos que operan de forma simultánea.

Siguiendo a Julia Kristeva ${ }^{19}$, Cros considera que todo texto está escrito con arreglo a otro: el texto nuevo reconstruye al antiguo y redistribuye los elementos de éste en el tejido del nuevo ${ }^{20}$. La genética del nuevo no puede hacer lo que quiera con la materia de los textos anteriores a la hora de redistribuirlos, reorganizarlos en el nuevo tejido, ya que los textos antiguos imponen ciertos trayectos de sentido

17. Nuestros planteamientos sobre las lecturas intertextual e interdiscursiva se ubican en la primera etapa de la sociocrítica desarrollada por E. Cros: al ir incorporando otras disciplinas y rediseñando su modelo teórico y metodológico, la sociocrítica se ha hecho más interdisciplinar, ha evolucionado, ha pasado por distintas etapas, las cuales reseña Amoretti "Por qué querer un hijo doctor? Análisis de Los problemas del gato" (mimeografiado, 1999) 1-14.

18. Edmond Cros, Literatura, ideología y sociedad (Madrid: Gredos, 1986) 101-102, 113.

19. Julia Kristeva, El texto de la novela (Barcelona: Lumen, 1974).

20. La noción de intertextualidad de Kristeva ha sido considerada por los posestructuralistas como descriptiva y omniabarcante: para ella todos los textos son intertextuales, noción poco útil cuando se trata de interpretar textos individuales. Para este grupo de críticos, es mejor referirse al conjunto de los procedimientos con que un texto se refiere a otro, como su pretexto (Pfister, 7). Además, esta noción se concentra casi exclusivamente en la superficie textual, desocializando el concepto bajtiniano de voz enmarcada o palabra enmarcada: a Kristeva le interesa más el texto como cruce o mosaico que el texto como arena conflictiva donde resuenan todas las voces sociales. 
dc los cuales el texto nuevo no puede salir ${ }^{21}$. Cros sitúa en el eje horizontal (eje del sistema modelizante) todo el material de lenguaje destinado a materializar el sentido y a informarlo, comola intertextualidad, el preconstruido y el preaserto ${ }^{22}$ : el intertexto es lo preasertado, lo preconstruido, esto es, el material lingüístico destinado a materializar el sentido. Para este crítico, la noción de intertextualidad implica que la historia y la sociedad sean consideradas como textos a semejanza de cualquier otra práctica semiótica ${ }^{23}$. En este sentido, la noción de intertextualidad de Cros se aproxima más al concepto bajtiniano de voz enmarcada y se distancia de los planteamientos de Kristeva.

Cros ubica la interdicursividad, en cambio, en el eje vertical. El texto es concebido como la materialización de discursos que mantienen entre sí relaciones múltiples y dialécticas. Este mecanismo remite a los fenómenos de conciencia: en él se materializan las estructuras mentales y las estructuras ideológicas producidas por la formación social. En este eje se lee el discurso del tiempo sobre el tiempo. El interdiscurso "traduce en operaciones semióticas, a través de múltiples trazados ideológicos, las contradicciones sociohistóricas en las que se haya inmerso el locutor ${ }^{24}$. La interdiscursividad se relaciona indirectamente con la formación social a través de la formación discursiva, la cual no es más que una concretización de la formación ideológica, producto de la formación social: a través del interdiscurso se puede llegar a la estructura económica ${ }^{25}$.

Dentro del planteamiento de la sociocrítica no es posible concebir discursos que funcionen de manera autónoma, pues estos se constituyen en relación con otros. Todo acto de palabra pone en juego

21. E. Cros, “Introducción a la sociocrítica. Conferencias 1 y 2”, Káñina, vol. X, n⿳ำ 1 (San José, enero-junio, 1986) 69-83.

22. Cros, Literatura, ideología y sociedad, 116.

23. E. Cros, El sujeto cultural. Sociocrítica y psicoanálisis (Buenos Aires: Corregidor, 1997) 122.

24. E. Cros, Literatura, ideología y sociedad, 116.

25. Cros, "Introducción a la sociocrítica", 78. 
un interdiscurso que imprime en el texto las huellas discursivas de una formación ideológica enmarcada en una formación social. El producto de mi escritura, apunta Cros, es un fenómeno de conciencia que utiliza una materia preconcebida y premodelizada: mi interdiscursividad reparte y redistribuye de otro modo los elementos de la intertextualidad. Una lectura interdiscursiva, entonces, tendría como finalidad identificar las huellas discursivas de una formación ideológica y los contornos de la formación social correspondiente.

$\mathrm{Al}$ entrar en la genética textual, la materia premodelizada no desaparece completamente: estos elementos van a ofrecer a mi escritura y a la genética textual lo que se puede llamar una opacidad, o sea, una resistencia a la desconstrucción: no se van a dejar diluir completamente en el nuevo texto. Estos elementos resistentes u opacos pueden entrar en contradicción con la interdiscursividad, llegando a ser una de las causas de las zonas de conflicto en el nuevo texto. Para poder hacer surgir las claves de decodificación conviene entonces averiguar cómo se reconstruye el material premodelizado en el nuevo texto $^{26}$.

Debe aclararse que en los planteamientos de Cros, la intertextualidad es entendida como práctica de escritura y no como efecto de lectura como en la propuesta de Riffaterre:

no es el intertexto el que va a desconstruirse, sino, más exactamente, su interpretante, es decir cierta idea de este intertexto; no es una antigua textualidad la que va a desconstruirse en la nueva, sino, de alguna forma, cierta manera de leer este primer texto. Pero esta descodificación queda asegurada en el marco de una gramática de la recepción, por medio del mismo dispositivo semiótico que, por otro lado, informa el interdiscurso, a menos que se suponga - y esto sería probablemente más exacto- que la descodificación que constituiría el interpretante no es más que

26. Cros, "Introducción a la sociocrítica" 79. 
un efecto de sentido producido por el genotexto ${ }^{27}$ (el destacado es mío).

Pese a estos postulados de la sociocrítica de Montpellier, nuestra práctica de lectura se ha visto obligada a conciliar los planteamientos de Cros con los de Riffaterre, y hemos partido de una propuesta que asume la intertextualidad no sólo como estrategia de escritura, sino también como estrategia de lectura, estrategia metodológica: la intertextualidad es un fenómeno que orienta la lectura del texto, dirige eventualmente la interpretación y sustituye la lectura lineal por una lectura estereométrica que nos permite comprender un texto por y con otro texto, un sentido por y con otro sentido. Es el modo de percepción del texto el que gobierna la producción de la significancia. En este modo de percepción, el lector toma conciencia de que las palabras significan por referencia a complejos de representaciones ya enteramente integradas al universo lingüístico ${ }^{28}$. O como bien lo sintetizan B. Hatin e I. Mason:

la intertextualidad es un aspecto tanto de la recepción como de la producción del texto. Lectores y escritores han de habérselas con la referencia intertextual como un importante aspecto de la construcción y deconstrucción de un texto ${ }^{29}$.

27. Literatura, ieología y sociedad, 102. En la tercera etapa de la sociocrítica, Cros sostiene que el texto cultural es "un fragmento del intertexto de un determinado tipo que interviene según modos específicos de funcionamiento en la geología de la escritura. Se trata de un esquema narrativo de natura doxológica en la medida en que corresponde a un modelo infinitamente retransmitido, en el cual, como consecuencia, se presenta como un bien colectivo cuyas marcas de identificación originales han desaparecido", Cros, El sujeto cultural. Sociocrítica y psicoanálisis (trad. R. Parra Valiente y E. Cros, Buenos Aires: Corregidor, 1997) 25

28. Michael Riffaterre, “L'intertexte inconnu", Littérature, no 41 (1981) 6.

29. B. Hatin, B. e I. Mason, "Intertextualidad e intención" (1990) en Teoría de la traducción. Una aproximación al discurso(trad. S. Peña, Barcelona: Ariel, 1995) 174. 
En este sentido, son intertextuales las referencias que el autor se propuso en el nuevo texto y que ha dejado en la superficie por medio de huellas, alusiones, citas y marcas reconocibles y comprendidas por el lector ${ }^{30}$.

No es sólo el escritor el que, para escribir sus textos deba hacerlo a partir de, contra, desde y con otros, sino también el lector, para poder leer, tiene que hacerlo con, desde, hacia y contra otros textos leídos y textualizados ya en su memoria. Así como el autor no es ya un yo, sino un sujeto transindividual, un nosotros, una interpersona, el texto terminará siendo un intertexto que materializa interdiscursos, y el lector tendrá que ser un interlector (otro intertexto): cada autor se abre a otro autor, cada texto a otro texto y cada lector a otro lector-leído, a otra lectura. En palabras de H. Bloom: "Todo poema es un interpoema, y toda lectura de un poema es una interlectura".

Ahora bien, mientras la sociocrítica de Montpellier parte de los lineamientos de Kristeva en el campo de la intertextualidad como práctica escriturística, la corriente representada por Gómez Moriana se adhiere a los planteamientos de Riffaterre y Eco que enfatizan en los mecanismos de percepción del lector, y ven lo intertextual como una marca pragmática de desciframiento: es el lector quien reconoce y ejecuta los elementos textuales para producir sentido (el que pueda construir y el que el texto le posibilite). En este caso, la lectura intertextual se convierte en una especie de espejo donde el observador se vuelve observado: por un lado, el lector se asoma a ver lo que tiene el texto, pero este acto activará el ojo del texto que verá en el lector los

30. Esta noción estructuralista de intertextualidad adolece de algunos problemas teóricos y metodológicos, discutibles a partir de las teorías de Barthes sobre texto, autor y lector: "el autor conserva su autoridad sobre su texto, la unidad y la autonomía del texto permanecen intactas y el lector no se pierde en una red laberíntica de referencias posibles, sino que se da cuenta de las intenciones del autor descodificando las señales y marcas inscritas en el texto" (Pfister, 8). Es como la noción de texto de U. Eco: "Un texto es un producto cuya suerte interpretativa debe formar parte de su propio mecanismo generativo", Lector in fabula, Barcelona: Lumen, 1981) 79. 
ICxtos leídos y almacenados en la memoria que en ese momento interactúa con la memoria del texto: en este instante la lectura deja de scr un mero acto y se convierte en proceso dialéctico. El lector se descubre como texto, poblado de lecturas, al mismo tiempo que se percata de que el texto también está saturado de otros textos, de otras lecturas desconstruidas, reorganizadas, redistribuidas y resemantizadas en el nuevo tejido textual. La intertextualidad no sólo existe en el objeto leído sino también en el sujeto lector: el lector es otro intertexto que se convertirá en mediador de la práctica lectoescriturística ${ }^{31}$.

En este sentido, la intertextualidad viene a plantear una ruptura epistemológica con la crítica tradicional al redefinir las prácticas de escritura y de lectura y las nociones de autor y texto. La noción y la práctica de la intertextualidad han provocado no sólo el descentramiento del sujeto, sino también la disolución de los límites del texto y la cómoda posición del lector receptivo y pasivo, complacido con ser guiado y dirigido por el texto que se explicitaba a cada momento, dando cuenta de los resquicios de la historia. Del creador se pasa al concepto de productor, ser ubicado, condicionado y determinado social, histórica y culturalmente, que trabaja una materia que no le es propiedad única, como tampoco le pertenecen las condiciones que gobiernan las transformaciones que ejerce sobre esa materia social que sc llama lenguaje: la palabra que trabaja estará poblada de las múltiples voces ajenas, como plantea Bajtín. El modelo estructural estático de los textos literarios queda atrás y da paso a esta fuerza expansiva, dialógica e interactuante de los textos entre sí y con otros, de los

31. María Amoretti ha explicado, cómo se lleva a cabo este proceso en Los problemas del gato, de Virgilio Mora Rodríguez, texto en el que la telenovela y el texto de ficción juegan el papel de interpretantes: "Una ficción se encarga de terminar la otra. La telenovela lee y valora así al texto literario y éste lee y valora también la telenovela, cada uno es recíprocamente interpretante del otro. Es esa la función de los textos culturales, servir de vehículo de lo dóxico, pero sobre todo, como mecanismos de un entendimiento recíproco entre autor, texto y lector: entendimiento recíproco que en estecasose reduplica, ya que el mismotexto cultural que sirve de interpretante al lector sirve, simultáneamente, de interpretante de sus vidas a los personajes del relato", Amoretti, “¿Por qué querer un hijo doctor. Análisis de Los problemas del gato”, 16. 
lectores con el texto y otros textos y lectores, y de los autores poblados de las voces socioideológicas de la época, la sociedad y la cultura que los ha amamantado.

La obra literaria no va a ser ya el producto de un ser privilegiado, como plantea Goldmann, capaz de tener una visión de mundo coherente, unitaria y homogénea, sino el resultado inacabado de una persona tan dominada, determinada y condicionada por las condiciones de su concreta existencia como cualquier otro ser. En razón de esto es que se hablará de que no hay una sola ideología que gobierna el texto y al sujeto productor, sino que en ellos convergen todos los discursos de los sujetos colectivos que hablan en él según sean las circunstancias en que ejerzan la palabra, según su procedencia social, histórica y cultural, dado que, como apunta Cros, "toda comunidad humana materializa las modalidades de su inserción histórica, espacial y cultural" a través de los discursos ${ }^{32}$.

De acuerdo con lo anterior, los textos serán una pluralidad de voces y de fuerzas confrontándose unas a otras dialógicamente. El texto termina siendo tributario de estas particulares condiciones contextuales y genéticas, de modo que el lector no puede dejar de lado este carácter polifónico e intertextual del texto a la hora de emprender un proceso de lectura: es la palabra habitada, valorada y preformada que trabaja el escritor la responsable de la polifonía y la intertextualidad en literatura. El lector debe tener presente que el nuevo texto no sólo desconstruye, reconstruye y redistribuye textos y discursos anteriores, sino que estas operaciones no son ni pasivas ni pacíficas: la mayoría de las veces las estructuras textuales y discursivas anteriores se van a resistir a ser sometidas por y en las estructuras del nuevo texto. El nuevo texto hallará en los textos y discursos anteriores

trayectos de sentido preestablecidos que van a ofrecer una mayor o menor resistencia a la modelización textual, en cuyo seno

32. Cros, Literatura, ideología y sociedad, 101. 
mantendrán islotes semióticos, microespacios de lecturas susceptibles de engendrar, bajo el efecto del eventual proyecto monosémico de la instancia narrativa, zonas conflictivas ${ }^{33}$.

En este sentido, el lector sociocrítico no sólo buscará los trayectos de sentido preestablecidos, sino también la forma en que son asumidos, elaborados, transformados y redistribuidos por el nuevo texto los textos y discursos anteriores, para luego determinar, cuál es la semántica que se construye en el texto a partir de los preconstruidos, preasertos y pretextos, qué tipo de operación ejerció el nuevo texto sobre el antiguo y viceversa, cuál fue la ruptura o continuidad semántica otorgada por los elementos intertextuales e interdiscursivos y si estos mecanismos han redimensionalizado o no las categorías espaciotemporales y de personaje, la historia. En definitiva, cómo hacen los mecanismos intertextuales e interdiscursivos que el texto sea otro texto y el lector otro lector, cómo posibilitan la metamorfosis del mundo mostrado o del universo ficcional, cómo construyen un sentido que aleja al texto de una relación directa con la sociedad y, finalmente, por qué las referencias históricas, geográficas y culturales no son transparentes, ni of recen una relación de correspondencia con categorías extratextuales, sino que aparecen opacadas por el proceso genético por el que el intertexto y el interdiscurso hacen pasar al texto.

Es Gómez Moriana quien explica que el nuevo texto puede hacer pasar al legado cultural por varias posibles operaciones: el calco discursivo o textual, la parodia, la subversión y la perversión. En palabras del mismo autor, la intencionalidad del nuevo texto frente al otro "puede ir de la simple reproducción a la ironía distanciadora, a la parodia o a la total subversión" 34 . Es tarea del lector identificar las marcas o señales textuales para determinar las posibles mutaciones a

33. Cros, Literatura, ideología y sociedad, 116-117.

34. Antonio Gómez Moriana, “La subversividad del discurso ritual. Una lectura intertextual del Lazarillo de Tormes”, Imprévue n” 1 (Montpellier, 1980) 66. 
que el nuevo texto somete las estructuras mentales y textuales del legado cultural. El texto, al introducir elementos procedentes de otros universos culturales, hace que estos funcionen en su interior de forma connotativa a causa de la multiplicidad de sus referentes. Al ser capaz de funcionar en diferentes isotonías, el texto puede engendrar lecturas diferentes, incluso opuestas. En este sentido, el lector no se encuentra frente a un producto acabado sino ante una "encrucijada de textos en diálogo".

Para poder comprender un texto de esta naturaleza -polifónico, en diálogo con otros textos y otros discursos-, se requiere de una lectura intertextual e interdiscursiva que tenga en cuenta esa referencialidad cruzada que rompe con toda lectura lineal ya que hace presente, por medio de las continuas alusiones, de forma virtual y sin necesidad de un desarrollo explícito, "las historias, ideas, mitos, que evocan en el lector sus componentes como consecuencia de la carga semántica de su pasado cultural" (Ibid). Los elementos tomados en préstamo por el nuevo texto se encuentran en tensión dialéctica entre su marca de origen y su funcionalidad en el nuevo sintagma que los incorpora.

De acuerdo con lo anterior, las lecturas intertextual e interdiscursiva tendrían como principal cometido, según Gómez Moriana:

a) identificar los préstamos textuales en el nuevo conjunto textual que los asimila;

b) estudiar las posibles interferencias de la carga semántica o marca de su pasado cultural en la nueva función adoptada;

c) determinar las posibles mutaciones o violaciones de las marcas al ser adoptadas por el nuevo texto, $y$

d) poner de manifiesto el entrecruzamiento de códigos en el texto (interdiscursividad) por medio de la identificación de los calcos discursivos ${ }^{35}$.

35. Gómez Moriana, 69-70. 
Si llegamos a captar la simultánea funcionalidad de cada elemento de un texto en el nuevo conjunto y el conjunto o conjuntos en que csc elemento se ordena en sus orígenes, podremos tener una mejor comprensión del proceso de significación.

Se trata de tener en cuenta en el estudio del texto esa 'marca' o carga semántica que llevan sobre sí sus componentes -como todo signo- por el mero hecho de haber estado integrados en otro $\mathrm{u}$ otros sistemas en su pasado cultural; pues su integración en el nuevo sistema que constituye el texto objeto de estudio -por muy original que sea el nuevo propósito y las funciones que en él se les asignen- no puede ignorar lo que pudiéramos llamar consagración por el uso, que pesa -como toda tradición- sobre esos elementos que lo componen ${ }^{36}$.

Las "marcas" o señales intertextuales e interdiscursivas coinciden con elementos tangibles del texto, son indicadores de la intertextualidad, pero no constituyen la referencia intertextual: "el intertexto no es un objeto de cita, sino un objeto presupuesto", apunta Riffate$\mathrm{rre}^{37}$. Estas señales pueden materializarse en el texto por medio de palabras, frases, cláusulas, secuencias, textos, estructura, tono, frases hechas. Todos estos elementos recuerdan, evocan el pre-texto, el preaserto, el pre-construido ${ }^{38}$. Pero, como podrá colegirse de los estudios intertextuales e interdiscursivos realizados y consultados ${ }^{39}$, estas

36. Gómez Moriana, 65.

37. Riffaterre, 4 .

38. B. Hatin y I. Mason anotan que los intertextos pueden provenir de: referencias explícitas, clichés, alusión, autocita, convencionalismo, proverbio y mediación. Apuntan, además, que las maneras en que una comunidad establece relación con grupos de textos pueden ser: genéricas, temáticas o tópicas, estructurales y funcionales, $172-173$ y 175.

39. María Amoretti, Debajo del canto(San José: Editorial de la Universidad de Costa Rica, 1987); Danielle Trottier, Juego textual y profanación (San José: Editorial de la Universidad de Costa Rica); Jorge Ramírez Caro, "Ritualización de la muerte en El Matadero. Estructura sacrificial", Imprévue no 2 (Montpellier, 1995), 51-66; Jorge Ramírez Caro, Los ritualesdel poder (Heredia: Editorial de la Universidad Nacional, 1997). 
lecturas son algo más que un simple proceso de búsqueda de alusiones textuales y discursivas. La referencia, cita, marca o señal, traza un camino, abre una puerta de entrada al texto que hace ir al lector a otros textos semantizados y latentes en su memoria intertextual. El lector debe tener presente que el texto anterior sólo debe ser visto "con arreglo a su contribución al código que va surgiendo a medida que el texto actual se desarrolla"40. Quien lee intertextual o interdiscursivamente, no ejecuta una lectura de equiparación ni de sustitución, no coteja lo evocado con lo presente: el envío o reenvío que nos propicia la "marca" no es para constatar, sino para determinar los juegos o procedimientos a que ha sido sometido el material antiguo en el nuevo, y la forma en que se codifica la realidad social, histórica y cultural en el texto.

En este sentido, las lecturas intertextual e interdiscursiva no son una actividad estática, ni tampoco permiten una traslación mecánica de las evocaciones con el nuevo texto: el nuevo texto no sólo desconstruye otros textos y otros discursos, sino también los componentes de ese mundo evocado: las categorías espaciotemporales y de personajes, la ideología y el punto de vista desde donde han sido mirados éstos. El texto antiguo, trabajado, reelaborado, desconstruido y redistribuido en el nuevo, posee su propia estructura, su propia lógica, su propia sintaxis y su propia semántica antes de ser integrado al nuevo. Igualmente el nuevo texto construirá su propia estructura, su propia lógica, su propia sintaxis y su propia semántica con elementos preexistentes. Por esta razón, no es posible establecer una relación de $\mathrm{A}=\mathrm{B}$ (en el entendido de que $\mathrm{A}$ sea el mundo del texto y $\mathrm{B}$ el mundo extratextual), ni sustituir una unidad por otra, código por código, personaje por personaje, espacio por espacio, tiempo por tiempo. Leer y analizar el entrecruzamiento dialógico que es el texto, permite ver un

40. Hatin y Mason, 171. 
número más complejo y múltiple de los sistemas y subsistemas semióticos que constituyen el texto objeto de lectura ${ }^{41}$.

La "marca", al evocar y atraer en la mente del lector un material anterior, rompe con la lectura lineal e introduce una nueva óptica desde la cual leer o seguir leyendo el texto. Esta marca llega a producir dos movimientos simultáneos en el proceso de lectura: uno que no sólo dcslee mi lectura sino también las lecturas anteriores a la mía, realizadas fuera de la óptica introducida por la marca y los textos evocados por ésta, y otro que relee y resemantiza los signos anteriores y futuros al momento en que el lector activa la marca presente en el texto o la que el texto activa en el lector. La marca pone en órbita un nuevo sistema de signos con los que se relacionará el lector de una nueva forma: reparando en la referencialidad cruzada, en la distribución y organización del tejido textual verá, cómo se produce una nueva constelación semántica dentro de la cual se va a resemantizar su lectura y las anteriores a la suya. La marca viene a ser como una mina que sólo estalla cuando alguien activa el mecanismo. Una vez producida la detonación, el caminante se ve obligado a repensar el camino anda do (por cuántas otras minas habré pasado y ni cuenta me di) y a tener más cuidado en el trayecto que le falta por andar (cuántas más estarán tendidas en el tramo que me queda). Pero a la vez, por efecto de la explosión semántica, muchos fragmentos de sentido quedan diseminados en el tejido textual, fragmentos que "contaminarán" la futura lectura.

El movimiento que ejecuta el lector es dialéctico y continuo: al conectarse con el texto evocado y su semántica, desteje su comprensión anterior del texto y da inicio a otro proceso hermenéutico mucho más plural o omniabarcante, en el que todas las piezas del texto se

41. Señalan B. Hatin y I. Mason: "Sería un error considerar que la intertextualidad es simplemente un proceso mecánico. Un texto no es una mera amalgama de 'trozos y partes' recogidos de textos anteriores. Tampoco hay que entender la intertextualidad como mera inclusión de una referencia ocasional en otro texto. Lo cierto es que las citas, las referencias que se hacen en un texto responden a alguna razón”, 167. 
dinamizan y adquieren vida por entrar a formar parte de otros sistemas semióticos, otros ejes estructurales y otra semántica con los que pueden dialogar, polemizar o distanciarse, o frente a los cuales pueden asumir una actitud paródica, subversiva o perversiva. El lector debe estar atento a esta sistemática fluctuación de sentido instaurada por las marcas intertextuales e interdiscursivas que pondrán de relieve el carácter anatrópico de la palabra. En este sentido, tanto la intertextualidad como la interdiscursividad vienen a ser una fuerza que ensancha los límites de la significancia.

El texto nuevo, al buscar una voz-texto desde, contra, con y para la cual decirse y hacerse leer, persigue ser reordenado, reorganizado y reconstruido de maneras múltiples por los lectores en el proceso de lectura: el mismo texto pide y replantea la lectura a través y desde los elementos culturales evocados. Esta inserción del texto dentro de una constelación semiótica y semántica ya asegurada y reconocida, más amplia, no hace más que asegurarle y aumentarle las posibilidades de una interpretación que tome en cuenta las múltiples voces que lo pueblan: la interpretación de un sentido no se puede hacer sin activar los que lo rodean (un sentido lleva y atrae a otro sentido) y la identificación de un texto detona los que están a su alrededor (un texto lleva y atrae a otro texto). La literatura termina, al fin de cuentas, siendo explicada con más literatura y construyendo su propio sentido con, desde, contra, por y para las múltiples voces que a ella se asoman y materializan.

Entonces, no es, como se ha dicho, el productor del texto quien sólo evoca o trabaja sobre textos anteriores, sino que el lector es invitado, atraído y solicitado (casi obligado por el texto) a que, para entender o comprender el texto, tenga que ponerlo en circulación y en diálogo con otros textos y con otros discursos: el vínculo intertextual e interdiscursivo del nuevo texto con los anteriores de su pasado cultural activa en el lector sistemas de conocimientos y creencias que sólo la conciencia dialógica del proceso de lectura puede hacer productiva. Así, en el proceso de lectura no sólo es leído e interpretado 
cl texto, sino que éste termina animando, leyendo e interpretando la conciencia intertextual y transindividual del lector. Una lectura intertextual e interdiscursiva es una lectura dialógica: el acto de significar está determinado no sólo por la existencia de textos y discursos previos, sino también por una práctica de lectura en el sujeto desconstructor.

Cabe decir que no basta con que la constitución del texto sea intertextual o una materialización de discursos, sino que quien desee leer intertextual e interdiscursivamente, debe tener una experiencia en el manejo de todo un corpus textual y discursivo para no hacer un mero reconocimiento semiótico y semántico de ese corpus a través de las "marcas", sino ponerlo en relación dinámica y dialógica con la procedencia social, histórica y cultural del productor del texto y el presente, donde se ubica el lector, y donde, para hacer estallar o detonar las "marcas", éstas deben decir algo al lector, activar en él su pasado o su experiencia cultural.

Además de establecer la cadena de referencias intertextuales e interdiscursivas, el lector debe identificar el hilo conductor, la estructura semiótica y semántica que aquellas evocan y construyen desde las fuentes de procedencia hasta el texto que las asume: atento a la mecánica que organiza el texto, no puede perder de vista la tendencia que éste suele tener a evocar y ocultar estructuras que pueden pasar desapercibidas para muchos lectores. Si uno repara en "El Matadero" (1874), de Esteban Echeverría, desde el inicio hasta el final, el texto se inscribe en un tiempo religioso - la cuaresma - que tiene como eje estructural la pasión y la muerte, el ayuno y la abstinencia, y reitera, por medio del intertexto y del interdiscurso, la muerte individual y social, incruenta y cruenta, privada y pública de los feligreses, los novillos, el niño, el toro y el Unitario. Quien no haya reparado en esto no habrá podido determinar la estructura que le da unidad temática, constructiva y ficcional al texto de Echeverría. Esta estructura es la sacrificial, a la que sólo se puede acceder desde una lectura y un análisis intertextual e interdiscursiva (Ramírez Caro, 1995 y 1997) ${ }^{42}$.

42. Hemos demostrado, además, que “El Matadero” posee una estructura inquisitorial que le da unidad temática y constructiva al texto de Echeverría: el texto noestá organizado sólo al rededor del sacrificio animal y humano, sino que éste se lleva a cabo, en el marco 
El lector que desee leer desde una perspectiva intertextual e interdiscursiva debe tener en cuenta, además, que la "marca" que hace posible identificar una alusión o referencia a otro texto o a otro discurso está ahí como un indicio de que algo ha pasado en la genética del texto. Corresponde al lector hacer evidentes estos fenómenos textuales: qué elementos permanecen del texto básico, por qué aparece sólo la mitad de una frase reconocible de un cierto universo cultural y la otra mitad corresponde a una nueva idea, a un nuevo universo semántico-cultural: ¿qué está sucediendo con las continuas desconstrucciones que el texto ejecuta sobre frases hechas? Por ejemplo: "Los campesinos han hecho su éxodo del campo a la ciudad, de su paraíso agrario a este valle de lágrimas". En el contexto costarricense, Valle Central ha sido sustituido por "valle de lágrimas", produciendo un caso de difracción semántica: el centro ya no se concibe como lugar de salvación del campo, sino como el espacio de condena. En cambio, el campo aparece como el paraíso para el centro.

Finalmente, recordemos que para Barthes, el texto quiere decir no sólo el texto mismo, sino también el espacio entre todos los textos en el que nos movemos y tenemos que movernos todo el tiempo. De modo que el intertexto sería esa imposibilidad de vivir fuera del texto $^{43}$. En este sentido, el lector vive en un universo, en un espacio textualizado, en un espacio donde se encuentran y cruzan múltiples textos y voces procedentes de miles de focos de cultura. Por esta razón, el lector no debe olvidar que no basta con descubrir los vínculos intertextuales de un texto, sino determinar su procedencia y su semántica dentro del nuevo; deberá recordar que cada vez que se introduce

de un mundo cerrado, hostil e intolerante, por motivos religiosos y políticos como un espectáculo público ejemplarizante del castigo que le espera a los rebeldes e insumisos, a los política y religiosamente "otros"; el Unitario es apresado, enjuiciado, torturado y ejecutado como un hereje, blasfemo e hijo del Demonio, inobediente y cuestionador del orden católico instituido. Ramírez Caro, Los rituales del poder. Estructuras sacrificial e inquisitorial en "El Matadero", 189-226.

43. Roland Barthes, Le plaisir du texte (Paris: Seuil, 1973) 59. 
una cita en un texto se culmina un proceso en el cual un signo viaja desde un texto base (la fuente) a otro terminal (el destino) y que en ambos espacios desempeña una función determinada. El área atravesada, desde un texto a otro, es lo que se conoce como espacio intertextual, y es ahí donde se modifican los conjuntos de valores unidos al signo: el valor semiótico del textobase sufre una transformación para ajustarse a su nuevo entorno y, gracias al proceso, actúa sobre él ${ }^{44}$.

Los textos de Borges muestran de manera explícita este viaje del texto a través de los demás textos y discursos anteriores; están construidos sobre, desde, a partir de, con, para y por un texto precedente, literario o no, existente o imaginario, canónico o apócrifo; transitan de esos otros textos al nuevo, atravesando fronteras espaciales, culturales y temporales. Al recordarnos este proceso, el escritor pone de manifiesto los mecanismos intertextual e interdiscursivo que sustenta la práctica de escritura que deben ser tomados en cuenta en el proceso de lectura: el lector está leyendo algo ya dicho en otra parte; el nuevo texto desconstruye, organiza y distribuye los sistemas y subsistemas semióticos anteriores y los pone a circular en otro contexto y para otro lector. Pero no crea el lector que el juego de citas que se da en los textos (borgianos o de otros) es una duplicación del sentido -o sentidos- que éstas tenían en sus textos de origen. Conviene saber, como sostiene Graciela Reyes, que:

un discurso puede mantenerse literalmente idéntico, pero cada enunciación nueva de ese discurso, cada cita, será diferente, porque se producirá en otro momento del tiempo, en otro contex-

44. B. Hatin y I. Mason, 168. No se crea que se pretende estudiar las fuentes al estilo de la historiografía literaria para determinar las influencias que ha recibido un autor. Una lectura intertextual e interdiscursiva no es una lectura de las fuentes, sino de la manera cómo el nuevo texto ha trabajado, asumido, desconstruido y redistribuido el texto y las voces anteriores y cómo las ha hecho producir sentido dentro del nuevo proyecto textual, dentro del nuevo programa semántico. 
to, y pervertirá el discurso original... no hay texto que no esté sometido a la perversión de ser leído o citado en otro tiempo; esa evocación lo alterará inevitablemente ${ }^{45}$.

La noción de espacio intertextual es de suma importancia, porque permite visualizar el trayecto seguido por el texto trabajado en, desde y por el nuevo: este trayecto está saturado de las múltiples voces, juicios y valoraciones que la sociedad, la historia y la cultura han emitido sobre el texto asumido y trabajado en, desde y por el nuevo texto. Esto es, el espacio intertextual permite explicar, cómo es que los textos anteriores vienen evaluados, traen las voces de las diferentes formaciones sociales que las han producido y por las que han atravesado: no se puede ver en el nuevo texto sólo el intertexto sin ver al mismo tiempo el interdiscurso y la interpretación que cierta época, cierta sociedad y cierta cultura han hecho del texto.

Con todo lo antes dicho se puede concluir que tanto el intertexto como el interdiscurso funcionan como factores tanto de producción como de transformación de sentido en el nuevo texto que se los apropia y trabaja. Además, ambos mecanismos pueden servir como marca pragmática indicadora de la naturaleza ficcional del texto en el que se analizan. Por último, tanto el intertexto como el interdiscurso sirven de guía en la actividad descifradora de la lectura, al proporcionarle al lector una puerta de entrada al nuevo texto y nuevas claves hermenéuticas para su desciframiento. Con esto podemos decir que no hay textos ni discursos autónomos: todo texto está constituido en relación con otros, al igual que todo discurso está concebido con arreglo y en relación con otros. Por eso, ningún texto literario puede ser comprendido fuera de su relación con otros textos y otros discursos.



